\title{
Platelet Monoamine Oxidase Activity in Alcoholics with and without a Family History of Alcoholism
}

\author{
Michael Soyka Brigitta Bondy Ellen Benda Ulrich Preuss Ulrich Hegerl \\ Hans-Jürgen Möller \\ Psychiatrische Klinik der Universität München, München, Germany
}

\section{Key Words}

Monoamine oxidase · Genetics · Alcoholism - Alcoholic subtypes

\begin{abstract}
A number of studies point at platelet monoamine oxidase (MAO) activity being reduced in alcoholics with a family history of drinking, this being a possible vulnerability marker for alcoholism. To test this hypothesis, we examined a group of recently detoxified alcoholics with high ( $n=25$ ) and low genetic loading for alcoholism ( $n=$ 28 ) and a group of healthy controls $(n=21)$. Clinical assessments were made using the SCID II interview for psychiatric disorders, the Family History Assessment Module and the Semi-Structural Assessment of Genetics in Alcoholism, a questionnaire especially designed for genetic studies. Platelet MAO activity with and without ethanol stimulation and the percentage of MAO activity with ethanol did not differ between groups. The only significant difference was a lower inhibition of MAO activity with ethanol in alcoholics both with and without a family history compared to controls. In patients with antisocial personality traits, platelet MAO activity was also not
\end{abstract}

\begin{tabular}{ll}
\hline KARGER & ( ) 2000 S. Karger AG, Basel \\
Fax +4161306 12 34 & \\
$\begin{array}{l}\text { E-Mail karger@karger.ch } \\
\text { www.karger.com }\end{array}$ & $\begin{array}{l}\text { Accessible online at: } \\
\text { www.karger.com/journals/ear }\end{array}$
\end{tabular}

found to be different from other alcoholics. Our findings question the hypothesis of reduced platelet MAO activity to be a possible vulnerability marker for alcoholism.

Copyright $\odot 2000$ S. Karger AG, Basel

Monoamine oxidase (MAO) is a mitochondrial enzyme involved in the metabolism and breakdown of several major neurotransmitter amines such as dopamine and serotonin. There are two distinct forms: type A which is involved in the metabolism of serotonin and norepinephrine and type $\mathrm{B}$ which degrades phenylethylamine and benzylamine. Only the latter form can be found in platelets [1]. The genes for MAO-A and MAO-B are located in the short arm of human $\mathrm{X}$ chromosome 8 (Xp 11.3). Over 50 variations of MAO-A and MAO-B activities have been shown in humans.

Decreased platelet MAO (MAO-B; EC 1.4.3.4) activity in alcoholics compared to controls has been demonstrated in numerous studies [2-7], although some studies failed to show this effect $[8,9]$. Since alcoholism is a very heterogenous disorder with multiple subgroups, more recent studies have tried to link reduced MAO-B activity in alcoholics with certain personality traits or family history of alco-

\footnotetext{
Michael Soyka, MD

Psychiatrische Klinik der Universität München, Nussbaumstrasse 7

D-80336 München (Germany)

Tel. +49 895160 5324, Fax +49 8951605617

E-Mail michael.soyka@psy.med.uni-muenchen.de
} 
Table 1. Characteristics of inpatients with regard to family history

\begin{tabular}{lccccc}
\hline & FHP alcoholics & FHN alcoholics & Controls & F/T value & Significance \\
\hline Gender, male/female & $22 / 3$ & $21 / 7$ & $9 / 13$ & & \\
Age, years & $37.1 \pm 7.4$ & $43.7 \pm 11.0$ & $33.7 \pm 11.1$ & 7.77 & 0.008 \\
Alcoholics & & & & \\
$\quad$ Alcoholism age of onset & $26.3 \pm 7.0$ & $31.7 \pm 9.0$ & & -2.09 & 0.041 \\
$\quad$ Daily alcohol intake, g/dl & $239.6 \pm 99.7$ & $206.9 \pm 97.81$ & & & n.s. \\
\hline
\end{tabular}

$\mathrm{F} / \mathrm{T}$ value from ANOVA or $\mathrm{t}$ test.

holism. In some studies, a reduced MAO-B activity in alcoholics was associated with type 2 alcoholism [10], a subtype which associated with high heritability, early age of onset and severe social and legal consequences of alcoholism [5, 11-15]. Unfortunately, a possible correlation of reduced MAO-B activity and certain subtypes of alcoholism could not be demonstrated in all studies. Yates et al. [16] were not able to demonstrate a reduced platelet MAO activity in type 2 alcoholics, and a more recent study by Parsian et al. [17] also failed to show differences in MAO-B activity between alcoholics and nonalcoholic controls, and between type 1 and type 2 alcoholics. The allele frequency distribution for the MAO-A and MAO-B dinucleotide repeats was different between the alcoholic and the control sample. A reduced MAO-B activity may also be associated with violence, aggressive behavior and antisocial personality traits [18, 19].

Especially the possible association of reduced platelet MAO-B activity and family history of alcoholism has attracted substantial attention in recent years. A reduced activity has also been shown in relatives of alcoholics [2, $4,20,21]$. The activity of MAO is genetically determined [22], and twin studies suggest a minimum heritability of 0.75 for platelet MAO activity [23]. Some studies show that individual platelet MAO activity is also quite stable over time [6,24], but this has been questioned by others $[25,26]$. MAO activity has been advocated as a possible vulnerability marker for alcoholism [27-29], although more recent studies in alcoholic families failed to show any clear pattern [30]. Still more studies are necessary to explore the possible link of MAO activity with family history of alcoholism.

The other major question adressed in this study is whether certain personality traits such as sensation seeking, impulsiveness and monotony avoidance may be linked with low platelet activity. Rommelspacher et al. [31] found a significantly lower platelet MAO-B activity in alcoholics with high novelty-seeking and impulsiveness scores as measured by the Tridimensional Personality Questionnaire [10, German version 32] but these findings also need further confirmation.

To further examine the possible role of reduced MAO activity as a vulnerability marker for alcoholism and its possible association with high genetic loading for alcoholism, we conducted a study in recently detoxified alcoholics with a high and low genetic loading for alcoholism.

\section{Subjects and Methods}

\section{Methods}

We examined 53 psychiatric inpatients who met the ICD-10 and DSM-III-R criteria for alcohol dependence and 21 sex- and agematched healthy controls (hospital staff and town community wellknown to the investigators). Patient characteristics are given in tables 1 and 2. As expected, patients with a positive family history of alcoholism were found to have a significantly lower age of onset for alcoholism. They also were younger on examination. Patients with antisocial personality (ASP) traits were exclusively male and had a higher daily alcohol consumption compared to other alcoholics (table 2). Patients had been detoxified and were abstinent for at least 14 days before testing. Patients did not have a history for any other major psychiatric disorder including affective disorder, schizophrenia or polysubstance abuse. The latter was ruled out both clinically and by toxicological urine analysis.

\section{Laboratory Investigation}

Thirty milliliters of blood were drawn by venipuncture using NaEDTA as anticoagulant $(10 \mathrm{mg} / 10 \mathrm{ml}$ blood $)$. After centrifugation at $130 \mathrm{~g}$ for $20 \mathrm{~min}$ at room temperature, the resulting platelet-rich plasma was spun down at $2,000 \mathrm{~g}$ for $15 \mathrm{~min}$ at $4^{\circ} \mathrm{C}$, washed once in phosphate buffer $\left(\mathrm{NaCl} 140 \mathrm{mmol} / \mathrm{l} ; \mathrm{Na}_{2} \mathrm{PO}_{4} 8.6 \mathrm{mmol} / \mathrm{l}\right.$; glucose 11 $\mathrm{mmol} / \mathrm{l}$; $\mathrm{pH}$ 7.2). The final pellet was immediately frozen at minus $70^{\circ} \mathrm{C}$, enzyme determination was carried out not later than 4 weeks after blood sampling.

For investigation of MAO-B activity the platelet pellet was thawed, homogenized using an Ultrathurrax, suspended in phosphate-buffered saline ( $\mathrm{pH}$ 7.4) to give a final protein concentration of $2 \mathrm{mg} / \mathrm{ml}$. Of this protein suspension, $100 \mu \mathrm{l}$ were incubated with the 
Table 2. Characteristics of inpatients with regard to antisocial personality

\begin{tabular}{lcccl}
\hline & ASPD & Non-ASPD & T/F value & Significance \\
\hline Gender, male/female & $19 / 0$ & $29 / 6$ & & n.s. \\
Age, years & $40.5 \pm 10.8$ & $39.8 \pm 7.1$ & & n.s. \\
Alcoholics $\quad$ & & & 0.053 \\
$\quad$ Alcoholism age of onset & $29.1 \pm 8.1$ & $31.0 \pm 11.0$ & & -1.98 \\
$\quad$ Daily alcohol intake, g/d & $278.9 \pm 160.3$ & $198.7 \pm 78.76$ & & \\
\hline
\end{tabular}

ASPD $=$ Alcoholics with antisocial personality disorder; Non-ASPD = alcoholics without antisocial personality disorder.

substrate ${ }^{14} \mathrm{C}$-tryptamine $(2.4 \mu \mathrm{mol} / \mathrm{l}$; Dupont-NEN) in absence or presence of $400 \mathrm{mmol} / \mathrm{l}$ ethanol in a total volume of $350 \mu \mathrm{l}$ for $30 \mathrm{~min}$ at $37^{\circ} \mathrm{C}$. The reaction was stopped with $400 \mu \mathrm{l} \mathrm{HCl}(2 \mathrm{~N})$, all further procedures were carried out on ice. After addition of $6 \mathrm{ml}$ toluol, the samples were thoroughly mixed, incubated for $10 \mathrm{~min}$ and centrifuged at $600 \mathrm{~g}$ for $10 \mathrm{~min}$ at $4{ }^{\circ} \mathrm{C}$. Four milliliters of the supernatant were mixed with $10 \mathrm{ml}$ scintillation fluid (Ultima Gold, Canberra Packard) and counted in a $\beta$-scintillation counter (Beckmann); efficiency $50 \%$. MAO-B activity was calculated as nanomoles of product formed per milligram protein per hour. All samples were measured in triplicate with an average deviation below $10 \%$.

\section{Study Sample and Questionnaires}

Alcoholic inpatients were divided into patients with (family history positive, FHP, $\mathrm{n}=25$ ) and without (family history negative, FHN, $n=28$ ) family history. Patients were defined as FHP probands if they had at least 1 first-degree relative and 1 additional relative with alcohol dependence reported. In the FHN group, patients did not have any relative with alcohol abuse or dependence.

Psychological assessments were made using the SCID II interview. ASP traits were determined using the SCID II questionnaire according to DSM-III-R diagnosis criteria. Alcoholics were subdivided into subjects with ASP disorder if they positively answered 3 or more out of 10 questions of the SCID II adult ASP disorder scale.

All the patients recruited in our study signed an informed consent according to the declaration of Hongkong (1989) and the guidelines of good clinical practice.

Family history of alcoholism was obtained using the Family History Assessment Module [33], a questionnaire for both alcoholic patients and their relatives. To confirm the patients reports, one of the patients' relatives without any known alcohol problem was asked about the patient and his family, if possible. Unfortunately, $60 \%$ of the study population reported to have no contact with any relatives or refused to let the investigators seek contact with any of their relatives.

All questionnaires were given to the patients after alcohol withdrawal. Criteria for alcohol dependence or other substance abuse were obtained using the SCID-II questionnaire according to DSMIII-R. Additional data concerning alcoholism were obtained using a translated German version of the Semi-Structured Assessment of Genetics in Alcoholism questionnaire [34], an instrument frequently used in genetic studies in alcoholics. Age of onset of alcoholism was computed using 3 items: first age of frequent drinking, first age of loss of control over alcohol intake and first age when social problems or

Platelet MAO and Family History of

Drinking problems with relatives, spouse or friends due to alcohol consumption appeared.

\section{Data Analysis}

Statistics were performed using SPSS Software (Ver. 6.1.3., SPSS Inc, Chicago, 1994). All MAO data were tested for normal distribution.

Differences of MAO activity between the alcoholic subgroups and controls were tested by a one-way ANOVA. A significance level of 0.05 was chosen for all statistical analyses.

\section{Results}

Platelet MAO activity was investigated in 53 alcoholic patients, defined as FHP $(n=25)$ or FHN $(n=28)$ and 21 healthy controls. Basal MAO-B activities were on a similar level in all groups (fig. 1). After addition of ethanol, the mean data were decreased in all groups, without being able to distinguish between FHP, FHN and controls (fig. 2). However, a significant difference could be found as far as the percentage of enzyme inhibition with and without ethanol is concerned. Thus FHP and FHN patients showed a lower percentage of ethanol inhibition of MAO-B activity than was observed in healthy controls $(F=6.01$, d.f. 2.73, $p=0.003$, fig. 3, 4).

MAO-B activity in male alcoholics $(n=44)$ did not differ from that in female ones $(n=9)$, neither in basal enzyme activity ( $4.03 \mathrm{vs} .4 .76 \mathrm{nmol} / \mathrm{mg} / \mathrm{h}$ ) nor after ethanol inhibition (3.31 vs. $3.99 \mathrm{nmol} / \mathrm{mg} / \mathrm{h}$ ).

Nineteen patients were found to meet the DSM-III-R criteria for ASP obtained by SCID-II interview. Platelet MAO activity in these individuals did not differ from those patients who did not meet the criteria $(n=35)$ or healthy controls (fig. 5, 6). The only statistical difference observed was a lower percentage of inhibition of MAO activity in both ASP-positive and -negative alcoholics compared to controls $(F=6.34$, d.f. $=2,72, p=0.003)$. 


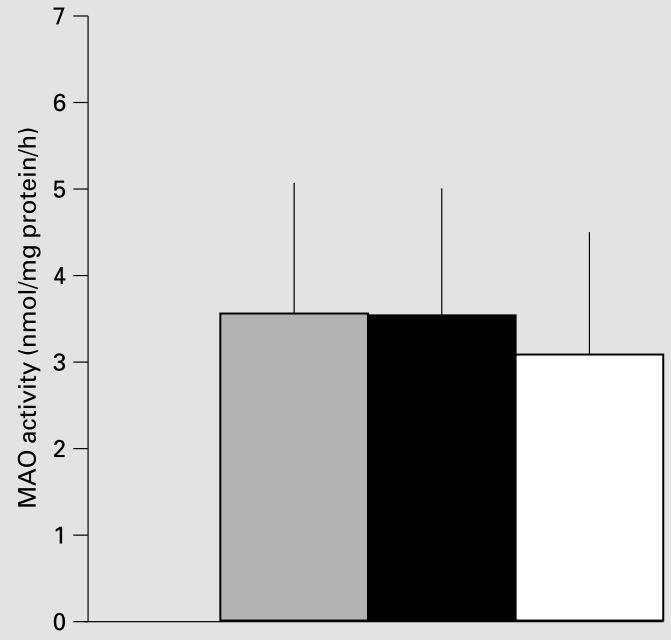

Fig. 1. MAO activity without ethanol in alcoholics with and without a family history of drinking and controls. $\boldsymbol{\square}=$ FHP; ; $=$ FHN; $\square=$ controls

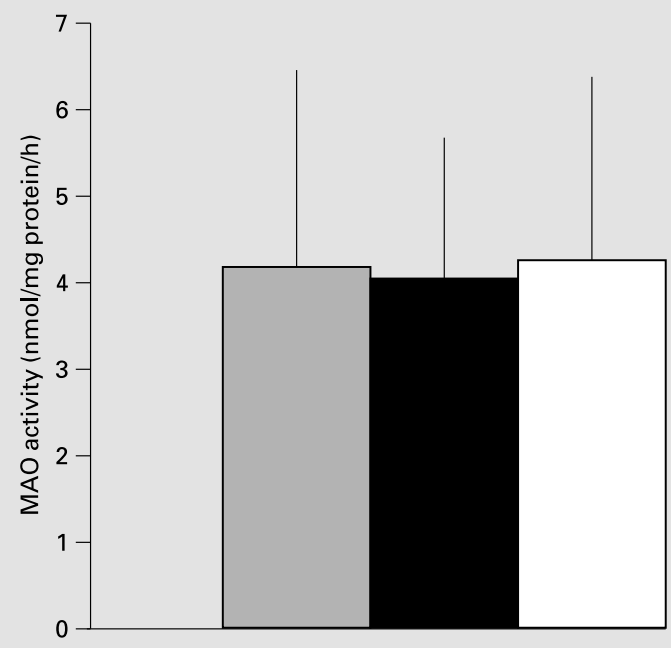

Fig. 2. MAO activity with ethanol in alcoholics with and without a family history of drinking and controls. $\square=$ controls

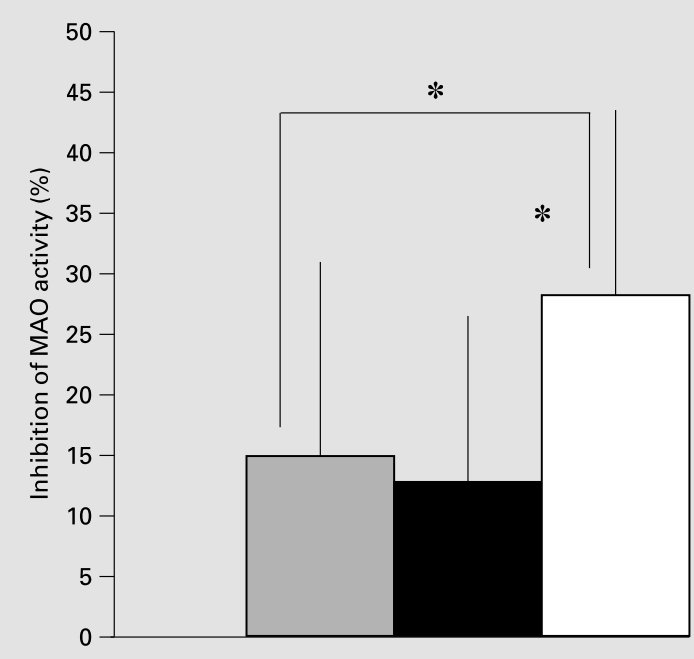

Fig. 3. Inhibition of MAO activity by ethanol in alcoholics with and without a family history of drinking and controls. $\square=$ FHP; 范 $=$ FHN $; \square=$ controls. ${ }^{*} \mathrm{p}<0.05$.

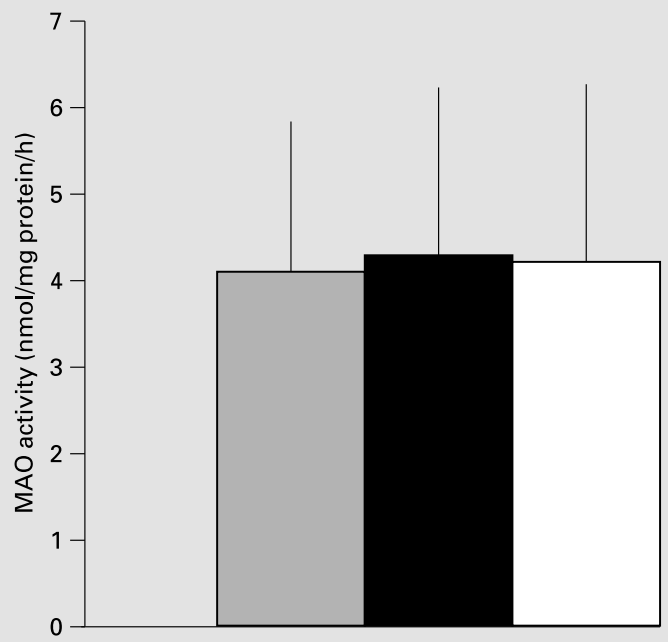

Fig. 4. MAO activity without ethanol in alcoholics meeting and not meeting criteria for ASP and controls. $\square=$ ASP; = non-ASP; $\square=$ controls. 


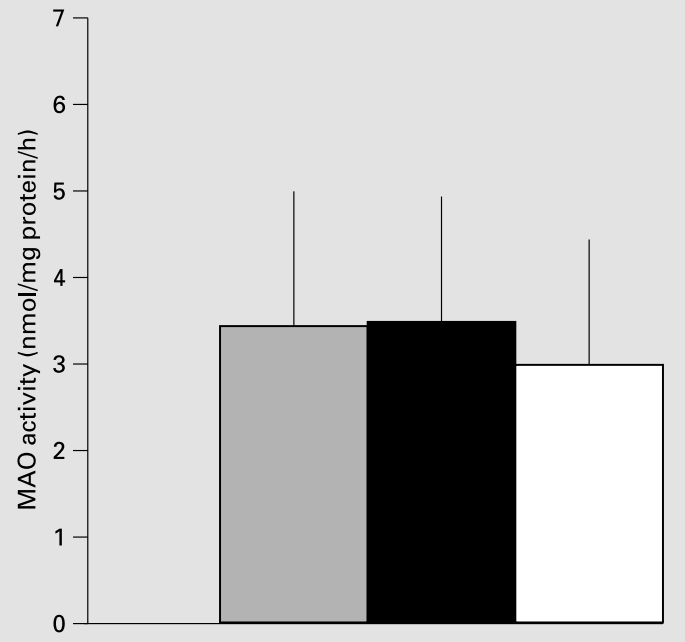

Fig. 5. MAO activity with ethanol in alcoholics meeting and not meeting criteria for ASP and controls. $\square=$ ASP; ; = non-ASP; $\square=$ controls.

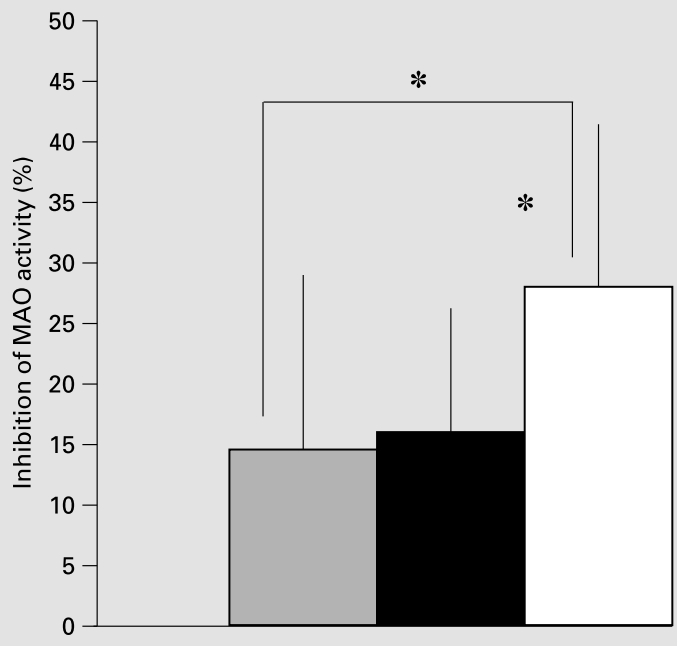

Fig. 6. Inhibition of MAO activity by ethanol in alcoholics meeting and not meeting criteria for ASP and controls. $\square=$ ASP; ; = nonASP; $\square=$ controls. ${ }^{*} \mathrm{p}<0.05$.

\section{Discussion}

In the present study, we were unable to demonstrate any significant differences in MAO activity both with and without ethanol inhibition between FHP and FHN alcoholics and healthy controls. We were also unable to find any significant differences concerning MAO activity in patients with and without ASP traits. The only significant difference was a lower percentage of inhibition of MAO activity with ethanol in patients compared to controls. The latter finding is consistent with previous studies as cited above.

A number of methodological problems may account for this result. Firstly, the number of patients studied in our sample was comparatively small, which was especially the case for patients with ASP traits.

Second, a number of possible variables may influence platelet MAO activity, as recently reviewed by Farren [35]. While Farren [35] concluded that MAO activity is stable in the post-withdrawal period from about 4 weeks of abstinence onward, and that it is unlikely that different assay methods contribute to the different findings in some studies, gender issues have been poorly examined. The COGA study recently reported that female alcoholics had a lower platelet MAO activity than female controls [36]. Other studies have shown mixed results [5, 16, 37, 38]. In our sample, we could not demonstrate any differences between male and female alcoholics, but the number of females was comparatively low. Another possible confounding variable is polysubstance abuse being of possible importance for the MAO activity, but this had been ruled out in our patients.

Thirdly, the concentration of ethanol used in our experiment $(400 \mathrm{mM})$ was relatively high. Although this is a dosage also used by other researchers, it might be of interest to study lower dosages of alcohol also. Still, taken the wide range of MAO activity into account, there is little reason to expect more robust findings.

While the possible role of platelet MAO activity as a vulnerability marker for alcoholism in general can be questioned on the basis of our own data and most of the studies published so far [35], its possible role as a marker for different types of alcoholics is still a matter of debate. Cloninger [39] proposed two types of alcoholics: type 1 being characterized by late age of onset, environmental precipitation, weak family history for alcoholism, absence of antisocial traits and fairly equal distribution between sexes, and the male-limited type 2 with early onset of alcoholism, lack of environmental precipitants and strong antisocial traits. Farren [35] concluded that if MAO activ- 
ity was indeed a marker for alcoholism, it might be expected to be more significantly diminished in the type 2 or the more strongly genetic form of alcoholism. Both hypotheses were examined in our sample, but we did not find any evidence for either. Some authors $[11,12]$ found a significantly diminished activity in type 2 alcoholics compared to type 1 alcoholics and controls. Pandey et al. [5] found lower MAO activity to be associated with young age, lower age of onset of alcoholism and higher frequency of family history of alcoholism. Similarly, Sherif et al. [40] reported a difference between type 2 alcoholics and controls, but not between alcoholics overall and controls. Unfortunately, other groups failed to find any differences between certain subtypes of alcoholics [16, 38, 41]. More recent provisional data of the large COGA study also did not show any differences in MAO activity between different subtypes of alcoholics [36]. Still, early-onset male alcoholics tended to have a lower platelet MAO activity.

Other psychopathological symptoms or personality traits may also be of relevance for platelet MAO activity, among others. However, similar to our findings, Farren et al. [38] and Anthenelli et al. [41] could not demonstrate differences in platelet MAO activity when divided by primacy of ASP disorder. Whether a history of affective disorder might be a risk factor for low platelet MAO activity in alcoholics is a matter of debate [5, 12], but the patients studied in our sample did not have any history of major psychiatric disorders such as depression. A number of personality traits might also contribute to different results in different clinical samples [for review see 35]. The most important issue might be a possible association with aggressive behavior and 'sensation seeking', and a possible negative correlation with impulsivity [14, 35, 42, 43].

In conclusion, our data suggest that platelet MAO activity in alcoholics with high genetic loading for alcoholism does not differ from alcoholics without family history for alcoholism or controls. Also, MAO activity in alcoholic patients with ASP traits did not differ from those in other alcoholics. Although platelet MAO activity seems to be controlled to a large extent by genetic factors, taking into account the wide range of data and the large number of clinical, biological and psychological variables being possibly associated with differences in MAO activity and the nonspecificity of reduced MAO activity at present, a reduced platelet MAO activity cannot be considered as a reliable vulnerability marker for alcoholism. Future research in this field should focus on special subtypes of alcoholics being characterized by certain biological, genetic or psychological characteristics.

\section{Acknowledgment}

This work was supported by Deutsche Forschungsgemeinschaft Grant No. Mo 538/5-1.

\section{References}

1 Garrick NA, Redmond DE, Murphy DL: Primate-rodent monoamine oxidase differences; in Singer JP, Van Korff RW, Murphy DL (eds): Monoamine Oxidase: Structure, Function, and Altered Function. New York, Academic Press, 1999, pp 351-359.

2 Alexopoulos GS, Lieberman KW, Frances RJ: Platelet MAO activity in alcoholic patients and their first-degree relatives. Am J Psychiatry 1983;140:1501-1504

3 Faraj BA, Lenton JD, Kutner M: Prevalence of low monoamine oxidase function in alcoholism. Alcohol Clin Exp Res 1987;11:464-467.

4 Major LF, Murphy DL: Platelet and plasma amine oxidase activity in alcoholic individuals. Br J Psychiatry 1978;132:528-554.

5 Pandey GN, Fawcett J, Gibbons R, Clark CD, Davis JM: Platelet monoamine oxidase in alcoholism. Biol Psychiatry 1988;24:15-24.

6 Sullivan JL, Stanfield CN, Maltbie AA, Hammet E, Cavenar J: Stability of low blood platelet monoamine oxidase activity in human alcoholics. Biol Psychiatry 1978;13:391-397.
7 Sullivan JL, Cavenar JO, Maltbie AA, Lister P, Zung WWK: Familial biochemical and clinical correlates of alcoholics with low platelet monoamine oxidase activity. Biol Psychiatry 1979; 14:385-394.

8 Tabakoff B, Hoffman PL, Lee JM, Saito T, Willard B, DeLeon-Jones F: Differences in platelet enzyme activity between alcoholics and nonalcoholics. N Engl J Med 1988;318: 134-139.

9 Giller EG, Hall H: Platelet Mao activity in recovered alcoholics after long-term abstinence. Am J Psychiatry 1983;140:114-115.

10 Cloninger CR: Neurogenic adoptive mechanisms in alcoholism. Science 1987;236:410416.

11 Sullivan JL, Baenzinger JC, Wagner DL, Rauscher FP, Nurnberg JI, Holms JS: Platelet Mao activity in subtypes of alcoholism. Biol Psychiatry 1990;27:911-922.

12 von Knorring A-L, Bohman M, von Knorring L, Oreland L: Platelet Mao activity as a biological marker in subgroups of alcoholism. Acta Psychiatr Scand 1985;72:51-58.
13 von Knorring A-L, Hallman J, von Knorring L, Oreland L: Platelet monoamine oxidase activity in type I and type II alcoholism. Alcohol Alcohol 1991;26:409-416.

14 von Knorring L, Oreland L: Personality traits and platelet monoamine oxidase in tobacco smokers. Psychol Med 1985;15:327-334.

15 Hallman J, von Knorring L, Oreland L: Personality Disorders According to DMS-III-R and Thrombocyte Monoamine Oxidase Activity in Type 1 and Type 2 Alcoholics. J Stud Alcohol 1996;57:155-161.

16 Yates WR, Wilcox J, Knudson R, Myers C, Kelly MW: The effect of gender and subtype on platelet MAO in alcoholism. J Stud Alcohol 1990;51:463-467.

17 Parsian A, Suarez BK, Tabakoff B, Hoffman P, Ovchinnikova L, Fisher L, Cloninger CR: Monoamine Oxidases and Alcoholism. I. Studies in Unrelated alcoholics and Normal Controls. Am J Med Genet 1995;60:409-416. 
18 Lidberg L, Modin I, Oreland L, Tuck JR, Gilner A: Platelet monoamine oxidase activity and psychopathy. Psychiatr Res 1985;16:339343.

19 Belfrage H, Lidberg L, Oreland L: Platelet monoamine oxidase activity in mentally disordered violent offenders. Acta Psychiatr Scand 1992;85:218-221.

20 Devor EJ, Abell Cw, Hoffman PL, Tabakoff B, Cloninger CR: Platelet Mao activity in type 1 and type 2 alcoholism. Ann NY Acad Sci 1994; 708:119-128.

21 Puchall LB, Coursey RD, Buchsbaum MS, Murphy DL: Parents of high risk subjects defined by levels of monoamine oxidase activity. Acta Psychiatr Scand 1980;76:172-182.

22 Hsu Y-PP, Powel JF, Sims KB, Breakfield XO: Molecular genetics of the monoamine oxidases. J Neurochem 1989;53:12-18.

23 Pedersen NL, Oreland L, Reynolds C, McClearn GE: Importance of genetic effects for monoamine oxidase activity in thrombocytes in twins reared apart and twins reared together. Psychiatr Res 1993;46:239-251.

24 Bridge TP, Soldo BJ, Phelps BH, Wise CD, Francak MJ, Wyatt RJ: Platelet monoamine oxidase activity: Demographic characteristics contribute to enzyme activity variability. J Gerontol 1985;40:23-28.

25 Takashashi S, Taui N, Yamane H: Monoamine oxidase activity in blood platelets in alcoholism. Folia Psychiatr Neurol 1976;30:455-462.

26 Brown JB: Platelet Mao activity and alcoholism. Am J Psychiatry 1977;134:206-207.

27 Buchsbaum MS, Coursey RD, Murphy DL: The biochemical high risk paradigm: Behavioral and familial correlates of low platelet monoamine oxidase activity. Science 1976;194:339_ 341.
28 Oreland L, von Knorring L, von Knorring A-L, Bohman M: Studies on the connection between alcoholism and low platelet monoamine oxidase activity; in Parvez S, Burov Y, Parvez $\mathrm{H}$, Burns E (eds): Progress in Alcohol Research, vol 1, Alcohol, Nutrition and the Nervous System. Utrecht VNU Science Press, 1985, pp 83117

29 Schalling D, Asberg M, Edman G, Oreland L: Markers for vulnerability to psychopathology: Temperament traits associated with platelet MAO activity. Acta Psychiatr Scand 1987;76: 172-182.

30 Suarez BK, Hampe CL, Parsian A, Cloninger CR: Monoamine oxidases and alcoholism. II. Studies in alcoholic families. Am J Med Genet 1995;60:417-423.

31 Rommelspacher H, May T, Dufeu P, Schmidt LG: Longitudinal observations of monoamine oxidase $\mathrm{B}$ in alcoholics: Differentiation of marker characteristics. Alcohol Clin Exp Res 1994; 18:1322-1329.

32 Dufeu P, Kuhn S, Schmidt LG: Prüfung der Gütekriterien einer deutschen Version des Tridimensional Personality Questionnaire (TPQ) von Cloninger bei Alkoholabhängigen. Sucht 1995;41:395-407.

33 Rice JP, Reich T, Bucholz KK, Neuman RJ, Fishman R, Rochberg N, Hesselbrock VM, Nurnberger JI Jr, Schuckit MA, Begleiter H: Comparison of direct interview and family history diagnoses of alcohol dependence. Alcohol Clin Exp Res 1995;19:1018-1023.

34 Bucholz KK, Cadoret R, Cloninger CR, Dinwiddie $\mathrm{SH}$, Hesselbrock VM, Nurnberger JI, Reich T, Schmidt I, Schukit MA: A new, semistructured psychiatric interview for use in genetic linkage studies: A report on the reliability of the SSAGA. J Stud Alcohol 1994;55:149_ 158.
35 Farren CK: Platelet monoamine (MAO) activity and alcoholism: Is there a genuine association? Addict Biol 1997;2:171-180.

36 Anthenelli RM, Smith TL, Eischen S, Tabakoff B, Schuckit MA: Platelet monoamine oxidase (MAO) activity in subgroups of alcoholics and controls: Results from the Collaborative Study on the Genetics of Alcoholism. Alcohol Clin Exp Res 1998;22:598-604.

37 Hallman J, von Knorring A-L, von Knorring L, Oreland L: Clinical characteristics of female alcoholics with low platelet monoamine oxidase activity. Alcohol Clin Exp Res 1990;14: 227-231.

38 Farren CK, Clare AW, Tipton KF, Dinan TG: Platelet MAO in subtypes of alcoholics and controls in a homogenous population. Psychiatry Res 1998;32:49-54.

39 Cloninger CR: A systematic method for clinical description and classification of personality variants. Arch Gen Psychiatry 1997;44:573588.

40 Scherif F, Hallman J, Oreland L: Low platelet gamma-aminobutyrate aminotransferase and monoamine oxidase activities in chronic alcoholic patients. Alcohol Clin Exp Res 1992;16: 1014-1020.

41 Anthenelli RM, Smith TL, Craig CE, Tabakoff B, Schuckit MA: Platelet monoamine oxidase activity levels in subgroups of alcoholics and controls: Diagnostic, temporal, and clinical correlates. Biol Psychiatry 1995;38:361-368.

42 Fowler CJ, von Knorring L, Oreland L: Platelet monoamine oxidase in sensation seekers. Psychiatr Res 1984;12:11-26.

43 Ward PB, Catts SV, Norman TR, Burroughs GD, McConaghy N: Low platelet monoamine oxidase and sensation seeking in males: An established relationship? Acta Psychiatr Scand 1987;75:86-90 